\title{
The Multi-Institutional
}

\section{Substructure-Superstructure Model of Understanding Causal Relations among Social Structures}

\author{
A. Olu Oyinlade*, David Finch, Zachary Christo \\ Department of Sociology and Anthropology, University of Nebraska, Omaha, USA \\ Email: ^aoyinlade@unomaha.edu
}

How to cite this paper: Oyinlade, A. O., Finch, D., \& Christo, Z. (2020). The Multi-Institutional Substructure-Superstructure Model of Understanding Causal Relations among Social Structures. Sociology Mind, 10, 149-164.

https://doi.org/10.4236/sm.2020.103010

Received: May 13, 2020

Accepted: June 8, 2020

Published: June 11, 2020

Copyright $\odot 2020$ by author(s) and Scientific Research Publishing Inc. This work is licensed under the Creative Commons Attribution International License (CC BY 4.0).

http://creativecommons.org/licenses/by/4.0/ (c) (i) Open Access

\begin{abstract}
Students of sociology first encounter an analysis of relations among social structures in the introductory sociology class where they learn that social realities are the products of social structures. And, throughout their academic journey in the acquisition of knowledge in the discipline, sociology students are expected to develop a deep understanding of the nature of the relationships among social structures and the consequences of such relationships to human realities. In this endeavor, students learn the causal relations of substructures and superstructures proffered by Karl Max (deterministic economic infrastructure) and Max Weber (deterministic ideological infrastructure). In both economic and ideological determinisms, one particular social structure is determinant of all other social structures and human social realities. In this study, the ideas of both Marx and Weber are critiqued for causal reductionism or the fallacy of a single cause which is antithetical to sociological reasoning of multi-factor causality. For a better understanding of causal relations among social structures and social realities, this study offers the Multi-Institutional Substructure-Superstructure Model (MISSMOD) as a more comprehensive causal explanation of society's infrastructure and superstructure relations, which nullifies the distinction (claimed by Marx and Weber) between the infrastructure and the superstructure.
\end{abstract}

\section{Keywords}

Karl Marx, Max Weber, Substructure, Superstructure, Economic Determinism, Ideological Determinism 


\section{Introduction}

This paper was instigated by a classroom discussion about three years ago in the introduction to sociology class of the first author. That day, the first author lectured on what constituted the substructure of society in Karl Marx's ([1859] 1970) economic substructure and Max Weber's ([1904-05] 2010) ideological substructure. He had explained that Marx claimed that the structural base of any society was the society's mode of economic production, and that the superstructure of any given society, comprising of such things as social institutions, organizations, culture, relationships and all human social phenomena were the consequences of the economic substructure of the society, hence, the term, economic determinism. Therefore, the superstructure of a capitalist economic substructure would be different from that of the socialist and communist substructures.

The lecture shifted to Weber's disagreement with Marx on what constituted the substructure, though both men agreed that every society comprised of a substructure that shaped its superstructure. The contention between the two classical thinkers was on what constituted the substructure of society. Addressing his class, the first author explained Weber's position that the mode of economic production was not the substructure of society, but a part of the superstructure. For Weber, the collective set of prevailing societal ideologies form the substructure of any given society, and all aspects of the society's superstructure are shaped by those ideologies, hence, ideological determinism. To illustrate this point, the first author provided an example of how Weber's explanations of the protestant ethics, more precisely, the doctrines of 1500s Calvinism, contributed to the patterns (spirit) of modern capitalism, to demonstrate the relationship between an ideological structural base and the location of the capitalist economy in the superstructure of society.

After the lecture, it was time for questions and discussions, and one student, the second author on this paper, asked a series of questions and challenged the idea of a single substructure of society claimed by both Marx and Weber. He probed the correctness and adequacy of a single substructure of society, by arguing that a single substructure determining the superstructure was possibly an oversimplification of the complex relationships between the substructure and superstructure of society. He critiqued both Marx and Weber for not being sufficiently comprehensive in their analyses and explanations of those relationships. He refused to accept the simplicity (as he described it) of one structural base shaping all human realities. He challenged the professor (first author) to be more critical about the likely complexity of the substructure of society and to reject the positions of both Marx and Weber. Upon accepting the student's challenge, both the first author and the student, and the professor's teaching assistant (the third author) embarked on a critical re-examination of Marx and Weber's substructure-superstructure relations. Consequently, we arrived at a more nuanced sociologically accurate and comprehensive model description of rela- 
tions of substructure and superstructure than found in economic and ideological determinisms. We term this model the Multi-Institutional Substructure-Superstructure Model (MISSMOD).

The process of developing MISSMOD included an affirmation of the centrality of social structures to the sociological enterprise and a review of the adequacy of the relationships between the substructure and the superstructure in the works of Karl Marx ([1859] 1970) and Max Weber ([1904-05] 2010) in explaining relations among social structures. Upon reviewing the works of both classical thinkers, we offer a critique of their works relative to the complexity of relations among social structures and social realities. And, lastly, we offer our more robust and nuanced MISSMOD explanation of relations of substructure and superstructure that gives greater insight into the complexity of relations among social structures and social outcomes.

\section{Centrality of Social Structures to Teaching Sociology}

The importance and centrality of the roles of social structures in sociology are well established in both the Sociological Imagination (Mills, 1959) and Invitation to Sociology (Berger, 1963) among many other sociological works. In what he called the "Promise of Sociology", Mills (1959) demonstrated the central role of social structures in sociological analysis by delineating how personal biography is integrally connected to society. He indicated that through the sociological imagination, what is incorrectly perceived as personal troubles are best understood as part of the larger general social issues generated by social structures. It is when perceived personal troubles are understood as general social phenomena that such troubles could be correctly diagnosed and resolved through collective efforts directed at structural change.

Similarly, to Mills (1959), Peter Berger asserted that the analysis of social structures was the central framework for the sociological understanding of human behaviors and social conditions. In his treatise, Invitation to Sociology, Berger (1963) explained the sociological perspective as the point of view that human experiences were the consequences of the workings of social structures rather than individual's free will. He explained that human behavior was neither the result of personal will nor accidents. If sociology was to be useful in explaining and predicting human behavior and conditions, sociology must investigate and explain how forces of social structures shape all social realities. Therefore, for Berger (1963), the point of sociology was to analyze the presence of general social forces of social structures in any specific phenomenon to be explained.

Consistently with Mills and Berger and the origin of the discipline, Elwell (2013) emphasized the centrality of macrosocial structures to the understanding and analysis of all social phenomena. In his Sociocultural systems: Principles of Structure and Change, Elwell (2013) borrowed ideas from Karl Marx, Max Weber, Émile Durkheim, and Herbert Spencer, to emphasize the importance of 
macro sociological structural analysis in answering various questions about society. He placed macro structures at the center of answers to questions about what accounted for the origin, survival, and evolution of sociocultural systems, what account for differential technological advancement among societies, what led to the evolution of capitalism from earlier economic systems, what caused the unequal production and consumption of goods and services within and among societies, and how government and economic activities affect communities (Elwell, 2013).

Given the aforementioned ideas of early social classical thinkers and the principles of the sociological perspective and the sociological imagination, to be sociological is to base explanations of all social phenomena on social structures. Decerning from the ideas of Keith and Ender (2004), the understanding of the deterministic nature of social structures to human social behaviors, social conditions, problems and solutions to problems is the raison d'etre of sociology. Therefore, if a sociology course is intended to educate students about sociological reasoning, the primary goal of the course, should be the transference (teaching) and erudition (learning) of the roles of social structure in human existence. This goal is well supported in the study by Percell, Pfeiffer and Sayed (2007) that found that the most frequently cited goal of the introductory course was the learning of the "social" (referring to social structures) part of sociology or the learning to think sociologically.

In that the raison d'etre of sociology as a discipline is the understanding of the relations of social structures and human realities, the quality of explanations of these relationships becomes important to the discipline. Students of sociology are expected to be well grounded in their understanding of social structures, relations among social structures and the outcomes of such relations to human behavior and social conditions. Specifically, relative to this study, the coverage of the concepts of society's substructure and superstructure, as part of the discussion of relations among social structures, deserve accurate and full explanations as students become introduced to the discipline.

While any number of learning objectives (such as preparing students for advanced courses in sociology, exposure to sociological methods of inquiry, and learning basic concepts in the discipline) may be determined for a sociology course by an instructor, the particular likely course objective of learning the roles of social structure in shaping human realities is the concern of this study. More specifically, our concern lies mainly in the explanation of relations among social structures that are explained as the substructure and superstructures of society in the works of Karl Marx ([1859] 1970) and Max Weber ([1904-05] 2010), for an understanding of how social structures shape human experiences. Because sociology is intended to give students a strong understanding and analytical reasoning regarding how social structures operate in society, the explanation of substructure and superstructure, and their relationships with each other, became the impetus for this study. 


\section{Relations of Social Structures in Economic and Ideological Determinisms}

\subsection{Karl Marx: Economic Determinism}

It is important to, first, indicate that despite the popularity of the term, "economic determinism", the term was not directly used by Karl Marx (McMurtry, 1973), but in his explanations of the roles of economic substructure of society, he persistently described how the economic structure was the base or foundation that "determined" all other social structures, social processes and social relationships in society. He used the German words, "bestimmt" and "bedingt" which translate to "determining" and "conditional", respectively, in the English language. Hence, the labeling of his work as economic determinism is accurately appropriate (McMurtry, 1973). The same can be said of ideological determinism. It is a term we use based on Weber's oppositional stand to Marx that human ideologies collectively formed the substructure that determined society's superstructure (Weber, [1904-05] 2010), hence, ideological determinism is as apposite to Weber as economic determinism is to Marx.

By economic determinism or a deterministic economic substructure, Marx referred to all economic processes or the totality of all means and relations of economic production of society, as the foundation of society which determined all other aspects of society termed the superstructure (Marx, [1859] 1970). This was also the essence of Marx's point of historical materialism, by which he indicated that the historical patterns of material production and distribution determined all aspects of society in each historical period (Marx, [1859] 1970). According to Marx, all historical characteristics and conditions of society generated from the series of economic activities carried out by society (Morrison, 2006). Because the economic activities of society determine the history of society, the modes of economic production of society, therefore, stand as the center of the development of the superstructure of society (Morrison, 2006; Ritzer, 1983). And, more concretely, Marx indicated that the economic substructure of society determined society's legal and political structures, philosophies, ideologies, literary, artistic and all forms of social consciousness (Marx, [1859] 1970).

The deterministic nature of economic substructure indicates that the bourgeoisie class, as owners of the forces of production, determines the prevailing notions of social consciousness by fostering only those notions and ideologies that promote its interests and blocking those that oppose its interests. The bourgeoisie class, therefore, is the ruling intellectual class of society. It provides material succor to promote the ideologies and the institutions of society consistently with its interests, and it withdraws such material support, when its interests are violated (McMurtry, 1973). By providing and removing material support from ideas and social institutions, the selection of the best ideas for the well-being of society is manipulated and controlled by the bourgeoisie class. This means that any existing superstructure (including all prevailing ideas) is the superstructure that is corresponded by the interests of the economic ruling-class. 
Therefore, according to Marx, the ruling (dominant) ideas of society in every historical epoch, are the ideas of the ruling material class (Marx \& Engels, [1846] 1947). That is, the class, which is the material force of society, is at the same time its ruling intellectual force. It (the ruling material class) controls the mental production of society and subjects the non-ruling material class (the proletariat class) to its mental production (Marx \& Engels, [1846] 1947).

When the dominant ideas of society represent those of the material force, it means therefore, that the nature of the substructure will also represent the ideas of the ruling material class (that is, the substructure produces the bourgeoisie class whose ideas reciprocally shapes the substructure). So, while Marx emphasized the economic substructure of society as the determinant of the superstructure, he also did acknowledge the reciprocal influence of the superstructure on the economic substructure (Althusser, 1971; Coser, 1977; Wu, 2006). As expressed by Coser (1977), Marx did indicate in his later works (our emphasis) that while the economic substructure determined the superstructure, the superstructure also acted upon the economic substructure. It is not the case that the superstructure is a mere effect of the substructure, but that a reciprocal influence exists between the sub and the superstructure (Coser, 1977). It must be emphasized, however, that this reciprocal relationship between the substructure and the superstructure was a later moderation to Marx's earlier dogmatic claim (our emphasis) of a linear causal relationship between the economic substructure and the superstructure (Coser, 1977). Also, the acknowledgement of the reciprocal influence, did not lessen Marx's promulgation of the preeminence of the economic substructure in determining the superstructure. Given the dual nature of social structures as both causal and caused (Sewell, 1992) and as constitutive and constituted (Ranson, Hinings, \& Greenwood, 1980), Marx's acknowledgement of reciprocal structural influences only gave recognition to this duality. Hence, for Marx, the economic substructure was both primarily shaping the superstructure, and, yet being shaped by its own progeny, the superstructural ideas of the intellectual ruling force.

\subsection{Marx Weber: Ideological Determinism}

In his opposition to Marx's economic substructural determinism, Weber argued that social life could not be explained simply by economic laws. All aspects of society could not be adequately explained by modes of economic arrangement, but by the combination of various ideologies that emerged in society at a given historical time (Weber, [1904-05] 2010). He indicated that no singular ideology or institution could dominate social life because the political, economic, legal and religious structures, and all other ideologies in society, individually and collectively shaped social life. No one single ideology shaped social life in isolation of other ideologies, as the various spheres of ideologies shaped (and are shaped) by human realities (Morrison, 2006).

Unlike Marx who identified the substructure of society as its economic ar- 
rangement, Weber explained that a society's economy was determined by the combination of all the ideologies of society. That is, the economy was part of the superstructure rather than the substructure. He argued this point with his explanations of the roles of religion, specifically, Calvinism and Protestantism, in the emergence of modern capitalism.

As explained by Weber ([1904-05] 2010), the Englishman and Catholic Priest, John Calvin, following in the footstep of the German Catholic Priest, Martin Luther, and the Protestant reform movement, criticized the Catholic Church for what he (John Calvin) considered the church's permissive doctrine of salvation through the cycle of atonement, confession and forgiveness. Calvin believed the church did not promote ascetism, hence, he designed a more restrictive measure for salvation for his followers (Weber, [1904-05] 2010). He preached the doctrine of predestination in which he claimed God had assigned all humans into one of two destiny categories; the saved and the damned, and there was nothing one could do to reverse his/her assigned category. The saved were those that God had saved and would grant everlasting life and grace. They were the ones for whom Jesus had died. And, the condemned were those that were destined for abandonment by God. They would perish and go to hell (Weber, [1904-05] 2010).

As Calvinists wanted to know who was saved and damned to reduce uncertainties about their destinies, they developed signs of salvation and damnation (Weber, [1904-05] 2010). They adopted the idea of the "calling" invented by Martin Luther to indicate that those who were called to salvation were those who achieved legitimate economic success through hard work, financial investments, diligence in their profession, asceticism and becoming men of vocation (Weber, [1904-05] 2010). Financial success through profit seeking became a practice among the 1500s Calvinists as evidence of their calling to attain salvation. In the process, Calvinists, by their religious calling, developed an obligation of self-interests for salvation by becoming economically enterprising through rational attitudes and behaviors in decision-making (Weber, [1904-05] 2010). In time, however, later generations of Calvinists stripped the calling of its religious and spiritual anchorages and transformed it into a rationalist orientation for success for the sake of success, as well as rationalist procedures for dealing with all areas of life including politics, arts, family, etc. (Edles \& Applerouth, 2015).

The popularity of economic activities of early Calvinists, by their calling, over time, permeated into other protestant denominations and became widely accepted as an alternative to the original calling espoused by Martin Luther. Systematically, over time, protestant rational economic practices gave rise to the ethos and practices of modern capitalism of rational economic behaviors of hard work, investments, savings, and accounting (Weber, [1904-05] 2010).

The point articulated by Weber was that capitalism, as an economy, was a superstructure determined by the beliefs and behaviors of early Calvinists, and eventually all protestants, through economic rationalization and the ascetic life- 
style demanded by their calling. Although, originally intended for guiding behavior for salvation, "the subsequent secularization of the calling was a major force contributing to the explosive growth of capitalism in the West, as businesses were organized on the basis of impersonal, methodical practices, aimed at the efficient production of goods and services" (Edles \& Applerouth, 2015: p. 177). It is also important to reinforce that Weber argued that the protestant ethic was only one (not the only) of the ideological causal factors of the modern spirit of capitalism. He indicated that it was important to, first, determine the direction and extent to which religion shaped the development of material culture. After this has been done accurately, the extent of the contributions of other ideological forces to the development of modern culture can, then, be assessed (Weber, [1904-05] 2010).

\section{Critiques of the Economic and Ideological Sub/Superstructure Relations}

Based on the central ideas of Marx's economic determinism and Weber's ideological determinism, we arrived at the following key critiques of the ideas of both thinkers. Our critiques are based on the shortcomings of the ideas of both thinkers vis-à-vis accurate sociological reasoning on relations of social structures.

\section{1) Monocausal Perspectives}

Both economic and ideological determinisms claim a monocausal perspective of relations among social structures. Each presents a perspective of one form of substructure, economic mode or ideologic, as shaping all human realities. This perspective reduces complex causal factors of human realities to one type of causal factor, contrary to sociology's recognition of multiple structural causal factors, such as outlined in popular books like Invitation to Sociology (Berger, 1963) and the Sociological Imagination (Mills, 1959).

\section{2) Linearity of Structural Relations}

Both economic and ideological determinisms view relations among social structures as mainly linear and unidirectional in their influences on one another. In both forms of determinisms, the substructure was claimed to linearly and unidirectionally shape the superstructure. Although Marx did indicate in his later writing that a reciprocal relationship could be established between the economic substructure and the superstructure of society, this claim, as earlier mentioned, was only a later moderation to his original ideas of economic determinism in which he was very dogmatic (our emphasis) about a causal linear direction between the economic substructure and the superstructure. In final assessment, our review found the one-directional linear cause-effect relationship between the substructure and superstructure most salient and dominant in the works of the two classical thinkers. Our observation and critique support those of other scholars as discerned from the comment that it was commonplace "to critique Marx's conception for being economistic; that is, for placing too much 
emphasis on the economy as the sole determinant of society, social relations, and socio-political institutions" (Wu, 2006: p. 29).

\section{3) Oversimplification of Complex Realities}

Neither the economic nor ideological substructural perspective, as presented by Marx and Weber, respectively, addressed the complex simultaneous direct and indirect interactional causal paths, an all-channel directional structural influences, among all societal social structures (as we described in the next section of this article). Contrary to the oversimplification of complex relations of social structures describes by Max and Weber (from our judgement), we argue that social structures interact and produce outcomes in much more complex ways than described in either economic or ideological determinism, and sociology instructors and students should consider additional models of explanations for relations among social structures. It is in this endeavor that we offer a more robust, nuanced and comprehensive approach to explaining relations among social structures.

\section{The Multi-Institutional Substructure-Superstructure Model (MISSMOD) of Society}

The Multi-Institutional Substructure-Superstructure Model (MISSMOD) of relations among social structures borrows from the consensus in the ideas of August Comte, Herbert Spencer and Emile Durkheim expressed by Coser (1977) that society was like an organism with many parts that interrelated in complex ways to produce good health for the organism. By this analogy, the MISSMOD assumes that society comprises of social institutions and various social structures that interrelate in complex ways to produce various outcomes in society. However, unlike an organism in which all its parts must work in harmony for the good health of the organism, the MISSMOD assumes that relations among social institutions and all social structures in society take multiple forms including consensus, cooperation, competition and even conflict. Our emphasis in the metaphor of society as an organism is not only in the cooperation and harmony among the structures of society, but in the fact that structures reciprocally shape one another regardless of their form of interaction, be it cooperation, competition or conflict.

The thesis of our MISSMOD is that no one single social structure, acting alone, determines the functioning of all other social structures. Rather, all social structures, working individually and collectively, interactively shape the functioning of one another. It is the collective functioning of all social structures that determine the functioning of every individual social structure and all social outcomes in society. The patterns of simultaneous reciprocal influences among social structures are complex and invalidate the existence of a distinct demarcation between a substructure and a superstructure, as each structure is simultaneously both sub (causal) and super (caused). Based on this thesis, the MISSMOD is based on the following specific assumptions: 


\subsection{Assumptions of the Multi-Institutional Substructure-Superstructure Model (MISSMOD)}

1) No society (or country) exists in isolation of all other world societies (or countries). The internal social structures of each society are influenced by forces of external or global societies. That is, the whole world is connected through various political, economic, cultural and other factors, hence, no society exists in isolation of other global societies. Therefore, as an example, the economic structure and conditions of any country are affected by those of other countries.

2) No one single substructure of a society singularly shapes all other social structures and all human realities in the society.

3) No distinct separation between the substructure and the superstructure exists in society. An all-channel form of cause-effect relationships exist among society's social structures, making a distinct separation of substructure and superstructure non-existing.

4) All social structures are multi-causal and multi-caused, and all social realities have multiple structural causes and consequences.

5) The broadest (macro) social structures of society are social institutions (broadest system of rules, agreements, arrangements and social designs), and all meso (large groups, large complex organizations, culture and systems) micro (small single organizations and entities) and idio (individuals and very small groups) social structures are subsets of the macro social institutions.

6) Social institutions (economy, religion, government, education, family) and their subset social structures simultaneously form both the substructures and superstructures of society. Examples of social institutions and their subset social structures include the structure of the economy (macro) comprising the substructures of the banking industry (meso), a business enterprise (micro) and a work team (idio). Education as a social institution (macro) comprises of structures that include local school districts (meso), the structure of particular schools (micro) and teacher committees (idio). Similarly, the social institution of government (macro) includes the structures of the national government (also macro), state government (meso), city government (micro) and city council (idio).

7) Simultaneous influences in both direct and indirect proportions exist amongst all social institutions and subset social structures.

8) Simultaneous interactions amongst all societal substructures and superstructures form the basis for all social realities.

\subsection{Elaboration of the Assumptions of MISSMOD}

We elaborate on the assumptions of the Multi-Institutional Substructure-Superstructure Model (MISSMOD) with the aid of Figure 1 and Figure 2. In Figure 1, the MISSMOD shows that any focal society is influenced by global or external social structures (like educational systems, government, religion, the economy and cultures of other societies). Such influences may be the result of population movements, trade, labor, cultural and scientific exchanges, as well as 
various forms of other corporate and inter-governmental relations between a focal society and other societies in the world. The various types of external influences will shape the development and maintenance of the social institutions of a focal society, and such institutions simultaneously shape one another and all social realities in the focal society.

Figure 1 further shows how all the social institutions of a society overlap at an intersection (the center of all the institutional blades in the diagram) where they may simultaneously shape one another in their interactions. The figure also shows how each social institution, represented by a fan blade, is shaped by the other four institutions, represented by the inserted four blades on each respective institutional blade. In the example of the magnified inserted blades in Figure 1 , we attempted to show how an understanding of the social institution of education is being directly shaped by forces of the other four social institutions, while at the same time, education is directly shaping the other institutions. These relationships are shown through the arrow lines from and to education and the other four institutions within a society, while the society is being simultaneously shaped by forces of external structures.

The point being made in Figure 1 is further elucidated in Figure 2 which shows various channels of interactions and influences among the social institutions of society. The large arrows in Figure 2 represent direct relationships, while the thin arrows represent indirect relationships among social institutions relative to their influences on the focal educational institution used as an illustrative example. The figure centers on explaining the various institutional forces that shape the policies and agreements of the education institution (that is, education as superstructure) and how the education institution, simultaneously,

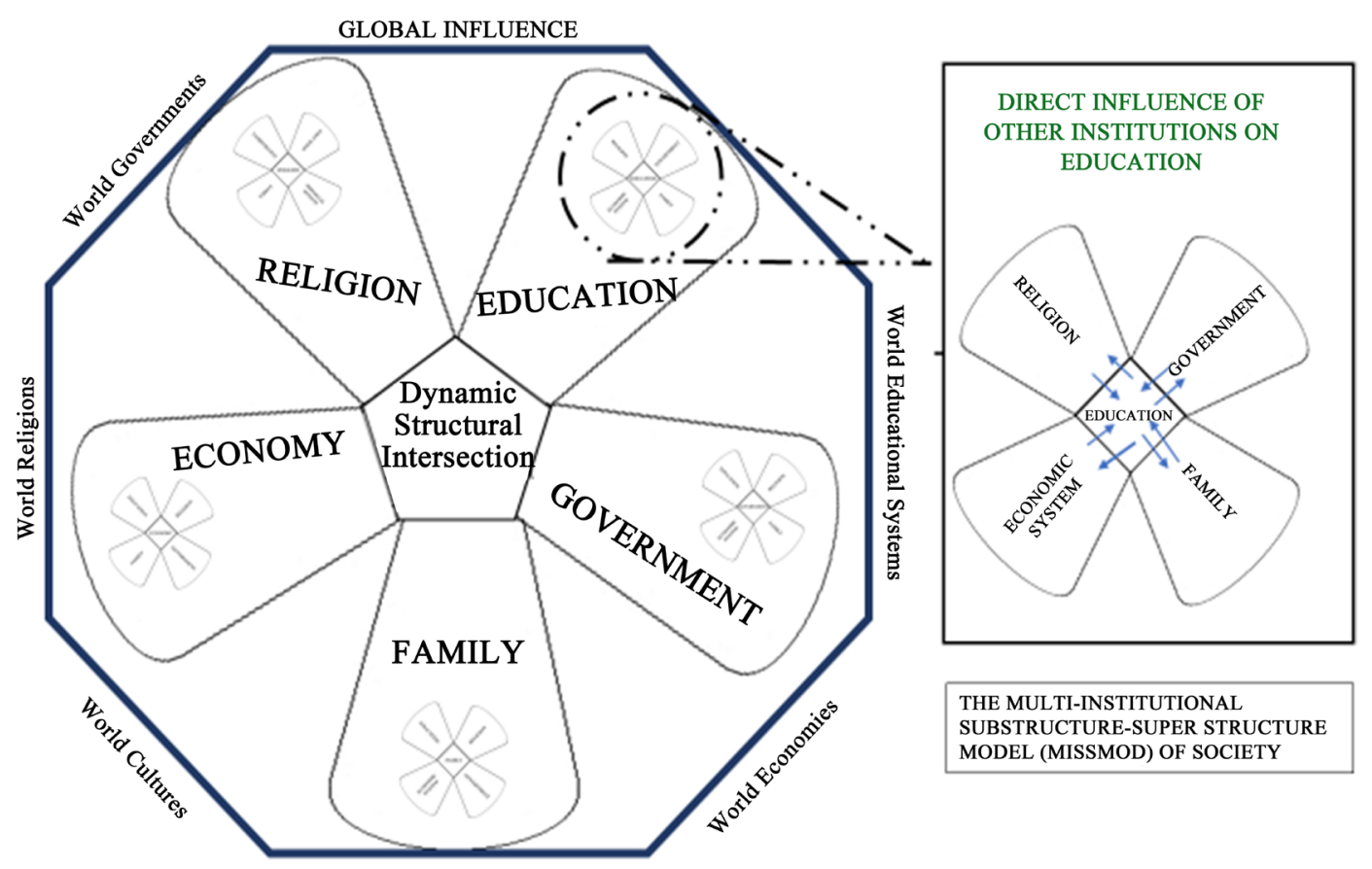

Figure 1. The Multi-Institutional Substructure-Superstructure Model of Society. 


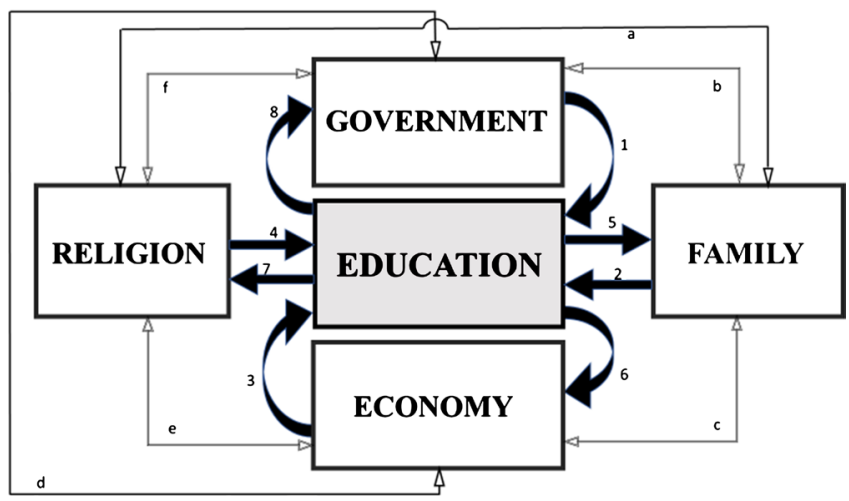

Figure 2. Direct and indirect relationships among education and all other social institutions.

contribute to shaping the other social structures (that is, education as substructure). All the big arrows from the institutions of government, family, economy and religion (relationships 1, 2, 3 and 4) to education, represent the simultaneous direct influences of those institutions on education. Also, all the big arrows from education to the other social institutions (relationships 5, 6, 7 and 8) show the simultaneous direct influences of education on each of the four institutions that shape it (education). This example illustrates the absence of a distinct separation of the substructure from the superstructure. Education, as the focal institution in this example, is simultaneously both sub-structural and superstructural.

It is important to also note that each institution that directly shapes education, is also simultaneously directly shaped by the forces of all other institutions (the thin lines in Figure 2). Hence, the direct influences (relationships 1, 2, 3, 4) of each non-focal institution on education are shaped by the influences of each of the non-focal institutions on one another. These influences are what we label as indirect influences of each non-focal institution on education. For example, as demonstrated in Figure 2, the direct influence of government on education (relationship 1, e.g. government monetary appropriation to schools and government laws that affect schools) may shape school policies, curriculum offerings and provision of equal access to education. These direct influences of government, however, are shaped by influences of family, the economy and religion on government. These relationships, represented in Figure 2 as relationships b, $d$ and $f$, are the indirect relationships or influences of government on education. That is, while government directly shapes (and is directly shaped by) education, the direct influences of government on education are shaped by the simultaneous influences of family, the economy and religion on government. Similarly, relationships a, b and c represent the indirect relationships of family on education. Had our focal example been another social institution (e.g. family) the focal social institution will replace education in the center of our diagram, and all direct and indirect relationships will be determined similarly to Figure 2.

\section{Conclusion}

In that the core perspective in sociology is the understanding of how the forces 
of social structures shape all human realities, we deem the relations of substructure and superstructure propounded by both Marx and Weber important for sociology students to learn. Sociology students need to be well versed in the workings of social structures because of the centrality of the knowledge of social structures to the discipline. The ideas of Max and Weber will, therefore, be a good steppingstone for students' learning about relations among social structures.

While acknowledging that both economic determinism and ideological determinism are worthy of learning, we argue that the single sub-structural causal model of society offered by both Marx and Weber falls short of adequately explaining societal conditions to students, especially advanced-level students. We argue that both economic and ideological determinisms are guilty of the fallacy of a single cause, causal oversimplification or causal reductionism, which is antithetical to sociological reasoning and problem-solving methods as stated by Mills (1959) and Berger (1963). We do not disregard Weber's collective ideological perspective of the substructure, but the collective of ideologies only constitute one form (category) of substructure, compared to what we advanced in the multi-institutional model that delineates both direct and indirect relations among social structures.

In that thorough sociological reasoning is multi-structurally oriented, and because social structures are intricately related in a complex web of cause-caused or determining-determined simultaneously reciprocal relationships, we conclude that a distinct demarcation between a substructure and a superstructure is a fallacy. We argue that each social structure conforms to the duality principle (Ranson, Hinings, \& Greenwood, 1980; Sewell, 1992) by shaping and being shaped by other social structures in a simultaneous chain of relationships. We, therefore, introduced the Multi-Institutional Substructure-Superstructure Model (MISSMOD) of relations among social structures, as an additional (and a more nuanced) model of explaining society to the single sub-structural approaches of Marx and Weber. We contend that the MISSMOD will give sociology students a better understanding of the complexity of structural impacts on social phenomena than found in both economic and ideological determinisms. We also assert that the MISSMOD approach to understanding complex causal relationships among social structures will give students a better preparation for grasping the complexity of sociological imagination than the single substructural perspectives of Marx and Weber.

A potential critique of MISSMOD for explaining relations among social structures vis-à-vis economic determinism and ideological determinism is possible. Some sociology instructors may prefer the simplicity of relations among social structures offered in economic and ideological determinisms, and therefore find MISSMOD complex, too comprehensive and/or cumbersome to explain to their students, especially undergraduate students, who are often presumed to be minimally ready for the rigor and sophistication of college level learning and 
reasoning. While this possible critique may be valid, we wish to indicate that MISSMOD is intended to serve as a progression of learning from the single-structure causal models of economic and ideological determinisms. After students had learned about the single substructural causal models, the complex and nuanced multi-structural causal model we propounded will be easier to grasp. The MISSMOD is intended as an additional perspective, rather than a replacement of the economic and ideological substructural perspectives of relations between the substructure and the superstructure.

The MISSMOD is also more accurate of sociological reasoning, than the single substructure models of Max and Weber, hence, it is worth the time for students to learn and to even improve upon it, as they may deem necessary through critical thinking. In addition, our MISSMOD is consistent with the position of other scholars such as Brent, Thompson and Vale who expressed that "in sociology there are typically several variables that predict or affect any variable, so it is also not uncommon to find multiple causal explanations in which a single variable is explained by multiple other variables" (Brent, Thompson, \& Vale, 2000: p. 226). Also, Mills (1959) asserted that sociological explanations (multi-causal factors) are important for students to acquire, if they are to view society through the prism of the sociological imagination.

Lastly, we argue that the use of MISSMOD to explain relations among social structures and human experiences to undergraduate students, especially in the introductory sociology course, will help students to correctly frame the discipline as multi-factor early in their sociological learning. Such correct framing will enhance the ability of students to avoid the fallacy of a single cause and to grasp the concept of intersectionality of multiple variables in shaping human behaviors and social conditions. As Wagenaar indicated, the introductory course "sets the stage for the sociology major and exposes most students to their only experience with sociology" (Wagenaar, 2004: p. 3). It is a course in which concepts that may frame the discipline for students ought to be given ample consideration in thorough and accurate presentation, especially because the course may be the only exposure to the discipline for many students (Keith \& Ender, 2004).

\section{Future Studies}

We acknowledge two potential shortcomings in this study that could be rectified in future studies by sociology scholars. This shortcoming is an elaboration of the direct and indirect structural reciprocal influences between the social structures of a focal society and those of global societies (or a specific foreign society). We mentioned such influences with a brief description in this study, and while our description may be sufficient for the purpose of this study, a deeper analysis would add value to the understanding of the realities of social structures within a society. We did not attempt such in-depth analysis because it was beyond the scope of this present study, but it is an important analysis that may lend greater depth to the understanding of relations among social structures across and 
within given societies. The World System Theory (Wallerstein, 1974, 2004) may serve as a useful springboard for the analysis of structural influences between societies, but such analysis require a focus on specific reciprocal relations among social institutions between a focal society and global societies rather than the general relations of subordination and super-ordination between core and periphery societies that characterize the World System Theory.

The second shortcoming in this study is the absence of an elaboration of the subset structures (meso, micro, idio) of social institutions in our analysis of relations among substructures and superstructures. This lack of elaboration was also intentional mainly for the purpose of emphasizing relations among social institutions, and, therefore, keeping our analysis and explanations manageable and relatively easy to follow. Because this study focused on demonstrating the limitations inherent in the determinisms of Marx and Weber, as well as showing the nonexistence of separate substructure and superstructure in society, our use of only social institutions was sufficient for our analysis, hence, making additional explanations that include analysis of other levels of social structures unnecessary. We, however, see much value in future studies that may replicate this study with analyses of all levels of social structures beyond social institutions. Such studies will be more intricate and elaborate in explaining the complex direct and indirect relationships among social structures that nullify a distinction between the substructure and superstructure beyond what is explained, albeit well demonstrated, in this study.

\section{Conflicts of Interest}

The authors declare no conflicts of interest regarding the publication of this paper.

\section{References}

Althusser, L. (1971). Lenin and Philosophy and Other Essays (Brewster, B., Trans.). New York: Monthly Review Books.

Berger, P. (1963). Invitation to Sociology; a Humanistic Perspective. New York: Anchor Books.

Brent, E., Thompson, A., \& Vale, W. (2000). A Computational Approach to Sociological Explanations. Social Science Computer Review, 18, 223-235. https://doi.org/10.1177/089443930001800210

Coser, L. (1977). Masters of Sociological Thought. New York: Harcourt Brace Jovanovich.

Edles, L. D., \& Applerouth, S. (2015). Sociological Theory in the Classical Era (3rd ed.). Los Angeles, CA: Sage.

Elwell, F. W. (2013). Sociocultural Systems: Principles of Structure and Change. Edmonton: Athabasca University Press.

Keith, B., \& Ender, M. G. (2004). The Sociological Core: Conceptual Patterns and Idiosyncrasies in the Structure and Content of Introductory Sociology Textbooks, 1940-2000. Teaching Sociology, 32, 19-36.

https://doi.org/10.1177/0092055X0403200102 
Marx, K. ([1859]1970). Preface to a Contribution to the Critique of Political Economy. New York: International Publishers.

Marx, K., \& Engels, F. ([1846] 1947). The German Ideology. New York: International Publishers.

McMurtry, J. (1973). Making Sense of Economic Determinism. Canadian Journal of Philosophy, 3, 249-259. https://doi.org/10.1080/00455091.1973.10716880

Mills, C. W. (1959). The Sociological Imagination. New York: Oxford University Press.

Morrison, K. (2006). Marx, Durkheim, Weber: Formations of Modern Social Thought. Thousand Oaks, CA: Sage Publications, Inc.

Percell, C. H., Pfeiffer, K. M., \& Sayed, A. (2007). What Should Students Understand after Taking Introduction to Sociology. Teaching Sociology, 35, 300-314. https://doi.org/10.1177/0092055X0703500401

Ranson, S., Hinings, B., \& Greenwood, R. (1980). The Structuring of Organizational Structures. Administrative Science Quarterly, 25, 1-17. https://doi.org/10.2307/2392223

Ritzer, G. (1983). Sociological Theory. New York: Alfred K. Knopf.

Sewell, W. H. (1992). A Theory of Structure: Duality, Agency and Transformation. American Journal of Sociology, 98, 1-9. https://doi.org/10.1086/229967

Wagenaar, T. C. (2004). Is There a Core in Sociology? Results from a Survey. Teaching Sociology, 32, 1-18. https://doi.org/10.1177/0092055X0403200101

Wallerstein, I. (1974). The Modern World-System: Capitalist Agriculture and the Origins of the European World-Economy in the Sixteenth Century. New York: Academic Press.

Wallerstein, I. (2004). World-System Analysis: An Introduction. Durham: Duke University Press. https://doi.org/10.1215/9780822399018

Weber, M. ([1904-05] 2010). The Protestant Ethic and the Spirit of Capitalism. Revised and Translated by Stephen Karlberg, New York: Oxford University Press, Inc.

Wu, W. (2006). Against Economic Determinism: Revisiting the Roots of Neo-Marxism in Critical Educational Theory. Journal for Critical Education Policy Studies, 4, 28-55. 